\title{
The effect of depressive symptoms on the association between radiographic osteoarthritis and knee pain: a cross-sectional study
}

\author{
Duarte Pereira ${ }^{1,2}$, Milton Severo ${ }^{1,2}$, Henrique Barros ${ }^{1,2}$, Jaime Branco ${ }^{3}$, Rui A Santos ${ }^{4}$ and Elisabete Ramos ${ }^{1,2^{*}}$
}

\begin{abstract}
Background: The progressive nature of knee osteoarthritis $(\mathrm{OA})$ leads to not only to physical but also to psychosocial decline; this aspect can influence knee pain experience, manifestations and inevitably diagnostic accuracy.

To analyze the role of depressive symptoms on the association between radiographic OA and knee pain, understanding the ability of knee pain symptoms to find out individuals with radiographic OA.
\end{abstract}

Methods: Data on 663 subjects was obtained by interview using a structured questionnaire on social, demographic, behavioural and clinical data. Painful knee was assessed regarding having pain: ever, in the last year, in the last 6 months and in the last month. Using factor analysis, participants were graded using a knee pain score, with higher scores representing more symptomatology. Depressive symptoms were evaluated with the Beck Depressive Inventory (BDI), and radiographic knee OA was classified using the Kellgren Lawrence (KL) scale; those with $\mathrm{KL} \geq 2$ were considered as having radiographic $\mathrm{OA}$.

Results: Knee pain was reported by $53.2 \%$ of those with radiographic $K L \geq 2$ and by $33.2 \%$ of those with radiographic $\mathrm{KL}<2$. The prevalence of depressive symptoms $(\mathrm{BDI}>14)$ was $19.9 \%$ among participants with radiographic $K L \geq 2$ and $12.6 \%$ among those with radiographic $K L<2(p=0.01)$. The association of knee pain with radiographic knee $\mathrm{OA}$ was higher in higher pain scores and in participants without depressive symptoms. Among participants with $\mathrm{BDI} \leq 14$ the likelihood ratio to identify patients with radiographic knee OA increased with increased pain scores: 1.02 for score 1; 2.19 for score 2 and 7.34 when participants responded positively to all pain questions (score 3). Among participants with depressive symptoms (BDI > 14) likelihood ratios were 0.51, 1.92, 1.82, respectively. The results were similar for both genders.

Conclusions: Knee pain scores increased ability to identify participants with radiographic $K L \geq 2$ in both sexes. However, the presence of depressive symptoms impairs the ability of knee pain complaints to identify patients with radiographic OA.

Keywords: Knee, Osteoarthritis, Pain, Radiographic OA, Depressive symptoms

\footnotetext{
* Correspondence: eliramos@med.up.pt

${ }^{1}$ Department of Clinical Epidemiology, Predictive Medicine and Public Health,

University of Porto Medical School, Alameda Prof. Hernâni Monteiro,

4200-319 Porto, Portugal

${ }^{2}$ Public Health Institute, University of Porto, Porto, Portugal

Full list of author information is available at the end of the article
} 


\section{Background}

Osteoarthritis (OA) is one of the most frequent causes of pain and disability, representing a substantial burden for the individual and for society [1-3]. Since incidence and prevalence increases with age, longer life expectancy will result in an increase in OA in the future [4,5].

Among the most common joint sites affected by OA, the knee is one of the most prevalent [6]. The knee is a weight-bearing joint, essential for function, and frequently associated with more reported pain in OA [6-8]. Accurate diagnosis and timely intervention is essential to minimize the consequences of knee $\mathrm{OA}$ and to slow its progress [9].

Knee OA diagnosis is based on radiographic changes and clinical examination [10]. According to recent recommendations, beside the radiographic evaluation, three symptoms (persistent knee pain, limited morning stiffness and reduced function) and three signs (crepitus, restricted movement and bony enlargement) were considered the most useful in the identification of OA patients [11].

Pain is thought to be an important marker of OA and is frequently the primary reason for seeking health care. It is correlated with radiographic symptomatic changes [12], strongly associated with other signs and symptoms and reliably predicts future disability [13]. Additionally, treatment strategies in $\mathrm{OA}$ are frequently focussed on pain relief and control [6]. However, there is a high variability in symptoms among individuals with radiographic findings making it difficult to identify patients with OA and to evaluate the progression of the disease among those already identified [11,14].

Several psycho-social determinants may explain differences in how people experience their symptoms [15]. Pain somatization is a frequent manifestation in depressed people and may predispose patients to report pain more often or even to exacerbate it [16]. Depressive symptoms are a common condition in adults and are frequently un-diagnosed [17]. On the other hand, it is also well-known that depression and its manifestations are prevalent among people with OA $[18,19]$. While chronic pain itself can cause or aggravate depressive symptoms, the impact of existing depressive symptoms on the experience of pain also needs to be explored [20].

Although recently several studies have evaluated the concordance between radiographic findings and knee pain and have found a strong association $[10,16,21]$, it is important to investigate the role of depressive symptoms in this relation. A comprehensive understanding of these factors can improve diagnosis and clinical approach to patients $[15,18]$. The aim of this study is to analyze the role of depressive symptoms on the association between radiographic OA and knee pain, understanding the ability of knee pain symptoms to find out individuals with radiographic OA.

\section{Methods}

\section{Data collection}

The study was performed using information collected as part of the EPIPorto cohort [22]. Briefly, this cohort evaluates non-institutionalized adults, resident in Porto, an urban centre located in northwest Portugal with almost 400,000 inhabitants. Participants were selected by random digit dialling and invited to visit the Department of Clinical Epidemiology, Predictive Medicine and Public Health for an evaluation, which included an interview based on a structured questionnaire on social, demographic, behavioural, clinical data and physical examination. The proportion of participation was $70 \%$.

The local ethics committee of S. João Hospital, a university hospital, approved the study protocol. All participants gave written consent to participate in the study, which was carried out in accordance with the Helsinki Declaration.

As previously reported, data was collected by trained interviewers using structured questionnaires plus a clinical interview and examination by a physician. We evaluated marital status (categorized on two categories: married/civil union and single/divorced/widow), years of education (measured as the number of successfully completed years of formal schooling), occupation (white collar, blue collar and other, including students, unemployed and those who had never had a job) and current occupational status (working, retired and other). We also evaluated as dichotomous variables (yes/no) regular physical activity practice, chronic medication, self-reported diagnosis of depression, knee OA, other chronic diseases and other rheumatic diseases.

Knee pain was evaluated using a set of "yes/no" questions. Firstly, participants were asked if they "ever had knee pain not related with any trauma or injury?" If participants gave a positive answer they were asked to answer (yes/no) to a further three questions: "In the last year did you have more than 3 knee pain episodes?"; "During the last 6 months did knee pain last longer than a week?"; "During the last month did you have knee pain?" To understand if these questions could be used to measure severity of knee pain, factor analysis for dichotomous variables was performed.

For depressive symptoms the Portuguese version of the Beck Depression Inventory (BDI) was used [23]. It is composed of 21 items, evaluating symptoms and attitudes, covering emotions, behavioural changes, and somatic symptoms in the previous 2 weeks before the evaluation. The final score ranges from 0 to 63 , with higher scores representing more severe depressive symptoms [24] and those who scored higher than 14 were considered to have depressive symptoms.

Body weight was measured to the nearest $0.1 \mathrm{~kg}$ using a digital scale $\left(\mathrm{SECA}^{\circledR}\right)$, and height was measured to the nearest centimeter using a wall-stadiometer $\left(\mathrm{SECA}^{\circledR}\right)$; 
then using body mass index (BMI) [weight (kg)/height $\left(\mathrm{m}^{2}\right)$ ] we classified participants in three categories $\left(<25.0 \mathrm{~kg} / \mathrm{m}^{2}\right.$ underweight or normal; 25.0 to $29.9 \mathrm{~kg} / \mathrm{m}^{2}$ overweight; $\geq 30 \mathrm{~kg} / \mathrm{m}^{2}$ obese) [25].

Weight-bearing radiographs of the knees (standard anterior-posterior and lateral views) were taken and graded according to the Kellgren Lawrence scale (KL): Grade 0, none: no visible features of OA; Grade 1, doubtful: questionable osteophytes or questionable joint space narrowing; Grade 2, minimal: definitive small osteophytes, little/mild joint space narrowing; Grade 3, moderate: definitive moderate osteophytes, joint space narrowing of at least 50\%; Grade 4, severe: joint space impaired severely, cysts and sclerosis of subchondral bone [26,27]. A subject was considered to have radiographic OA if the KL score at least on one side was greater or equal to two [14]. Radiographs were scored only by one experienced reader that was unaware of the participants' clinical data. In order to estimate the intra- observer reliability we calculated the Cronbach's Alpha [28] which was 0.9 and allowed us to assume as very good our intra-observer reliability [29].

\section{Participants}

From the 2485 participants of the EPIPorto cohort that participated at the baseline evaluation, 1682 were reevaluated during the follow-up performed between 2005 and 2008. The first 1000 participants were systematically invited. Compared with the 1682 participants evaluated, participants with radiographic evaluation were significantly lower educated [8.79 (5.07) vs. $9.26(5.45), \mathrm{p}<$ $0.01]$ and had a lower proportion of females $(58.4 \%$ vs. $65.3 \%, \mathrm{p}<0.01)$. From the first 1000 participants systematically invited to do radiographs, we obtained 907 knee radiographs; from these 13 participants had unreadable or incomplete knee radiographic evaluation and 231 had missing data for BDI.

Table 1 Comparison between included and excluded participants

\begin{tabular}{|c|c|c|c|c|}
\hline \multirow{2}{*}{\multicolumn{2}{|c|}{ Age (years) Mean (SD) }} & \multirow{2}{*}{$\begin{array}{c}\text { Excluded } \mathbf{n}=\mathbf{3 3 7} \\
56.5(14.1)\end{array}$} & \multirow{2}{*}{$\begin{array}{c}\text { Evaluated } \mathbf{n}=\mathbf{6 6 3} \\
58.0(15.2)\end{array}$} & \multirow{2}{*}{$\frac{\text { p-value }}{<0.01}$} \\
\hline & & & & \\
\hline Sex $n(\%)$ & Female & $197(58.5)$ & $371(56.0)$ & 0.45 \\
\hline \multirow[t]{2}{*}{ Marital status n (\%) } & Married/civil union & $238(70.6)$ & $454(68.5)$ & 0.46 \\
\hline & Single/divorced/widow & $99(29.4)$ & $209(31.5)$ & \\
\hline \multirow[t]{4}{*}{ Years of education $n(\%)$} & $0-4$ years & $92(27.3)$ & $202(30.5)$ & 0.77 \\
\hline & $5-9$ years & $89(26.4)$ & $172(25.9)$ & \\
\hline & $10-12$ years & $56(16.6)$ & $104(15.7)$ & \\
\hline & $\geq 12$ years & $100(29.7)$ & $185(27.9)$ & \\
\hline \multirow[t]{3}{*}{ Occupation n (\%) } & White collar occupations & $226(67.1)$ & $422(63.6)$ & 0.53 \\
\hline & Blue collar occupations & $79(23.4)$ & $167(25.2)$ & \\
\hline & Other (unemployed, student, never had a job) & $32(9.5)$ & $74(11.2)$ & \\
\hline \multirow[t]{3}{*}{ Current occupation status $\mathbf{n}(\%)$} & Working & $157(46.6)$ & $294(44.3)$ & 0.74 \\
\hline & Retired & $133(39.5)$ & $267(40.3)$ & \\
\hline & Other (unemployed, student, never had a job) & $47(13.9)$ & $102(15.4)$ & \\
\hline Regular Physical Activity n (\%) & Yes & $160(47.4)$ & $325(49.0)$ & 0.65 \\
\hline Chronic medication $\mathbf{n}(\%)$ & Yes & $115(34.1)$ & $212(32.0)$ & 0.49 \\
\hline \multirow[t]{4}{*}{ Self reported diagnosis $\mathbf{n}(\%)$} & Knee OA & $38(11.3)$ & $87(13.1)$ & 0.40 \\
\hline & Other rheumatic disease & $12(3.6)$ & $26(3.9)$ & 0.78 \\
\hline & Depression & $90(26.7)$ & $183(27.6)$ & 0.76 \\
\hline & Other chronic disease & $130(38.6)$ & $240(36.2)$ & 0.46 \\
\hline \multicolumn{2}{|c|}{ Height $(\mathrm{cm})$ Median (25th-75th percentile) } & $161(155.1-168.3)$ & $160.8(154.0-168.0)$ & 0.42 \\
\hline \multicolumn{2}{|c|}{ Weight $(\mathrm{kg})$ Median (25th-75th percentile) } & $69.8(61.2-79.1)$ & $69.7(60.0-79.0)$ & 0.73 \\
\hline \multirow[t]{3}{*}{ Body mass index $\left(\mathrm{kg} / \mathrm{m}^{2}\right) \mathrm{n}(\%)$} & $<25.0 \mathrm{~kg} / \mathrm{m}^{2}$ & $118(35.0)$ & $222(33.5)$ & 0.81 \\
\hline & $25.0-29.9 \mathrm{~kg} / \mathrm{m}^{2}$ & $152(45.1)$ & $314(45.8)$ & \\
\hline & $\geq 30.0 \mathrm{~kg} / \mathrm{m}^{2}$ & $67(19.9)$ & $137(20.7)$ & \\
\hline Knee Pain ("ever") & Yes & $133(39.5)$ & $280(42.2)$ & 0.40 \\
\hline \multicolumn{2}{|c|}{ BDI score Median (25th-75th percentile) } & $6(3-12)$ & $7(3-12)$ & 0.59 \\
\hline
\end{tabular}


After the exclusion process, data on 663 participants (371 females and 292 males) were analysed. The overall median (25th-75th percentile) age was 58 (48-67) years and the overall median BDI score was 7(3-12). Depressive symptoms $(\mathrm{BDI}>14$ ) were found in $28.5 \%$ of the participants and $17.7 \%$ presented both knee pain and depressive symptoms. As shown in Table 1, the 337 participants not included in the analysis were younger than those included [56 (47-66) vs. $58(48-67)(p<0.01)]$, but no other characteristics were significantly different among the two groups.

\section{Data analysis}

Continuous variables were described by mean (standard deviation) for variables with a normal distribution and by median (25th-75th percentile) for skewed distributions. Comparisons were tested using independent t-test for means, Mann-Whitney test for non-parametric distributions and qui-squared for proportions. To estimate the association of pain score and radiographic knee OA with depressive symptoms (BDI $\geq 14$ ) we used odds ratio (OR) and their 95\% confidence interval (95\% CI) calculated by logistic regression, adjusted for age, BMI and gender. Data analysis was performed using $R^{\circ}$ statistical software, considering a significance level of $5 \%$.

The dimensionality and internal consistency of knee pain questions was assessed by factor analysis for dichotomous variables (latent trait model) and Cronbach's Alpha, respectively. The ability of the knee pain score to discriminate between patients with or without radiographic $\mathrm{KL} \geq 2 \mathrm{OA}$ was summarised by sensitivity, specificity and likelihood ratios $(\mathrm{LR}=$ sensitivity/( 1 - specificity $))$ $[30,31]$, stratifying by sex and BDI score.

\section{Results}

Factor analysis for knee pain questions (dichotomous variables) identified only one factor and all items showed a factor loading higher than 0.86, and a global Cronbach's Alpha of 0.66 (Table 2). So we decided to consider these items as a score for knee pain and we classified participants as having no knee pain (score -1 ), knee pain but no other positive answer (score 0), and score 1 , score 2 or score 3 , according to the number positive answers. Overall radiographic knee $\mathrm{OA}(\mathrm{KL} \geq 2)$ was present in $45.4 \%$ of the participants and $42.2 \%$ reported "having had knee pain not related with any trauma or injury". Stratifying by radiographic classification, knee pain was reported by $53.2 \%$ of those with radiographic $\mathrm{KL} \geq 2$ and by $33.2 \%$ of those with radiographic $\mathrm{KL}<2$. Also, the proportion of participants with higher pain scores was larger among those with radiographic $\mathrm{KL} \geq 2$ (Figure 1).

We found that participants with higher pain scores had higher odds of having depressive symptoms. After adjustment for age, BMI and gender and considering participants with no pain (pain score -1 ) as reference category we found: $\mathrm{OR}=1.22(95 \% \mathrm{CI} 0.53 ; 2.79)$ for pain score $0, \mathrm{OR}=1.71(95 \% \mathrm{CI} 0.77 ; 3.77)$ for pain score $1, \mathrm{OR}=3.51(95 \%$ CI 1.92; 6.44) for pain score 2 and $\mathrm{OR}=5.64(95 \% \mathrm{CI} 2.85 ; 11.16)$ for pain score 3 .

The association between pain score and radiographic knee OA by categories of depressive symptomatology is presented in Table 3. The odds of having radiographic knee OA $(K L \geq 2)$ was higher in participants with higher scores of pain, both in patients with and without depressive symptoms; however the differences were higher among those with $\mathrm{BDI}<14$, even after after adjustment for age, BMI and gender.

The sensitivity, specificity and likelihood ratio regarding each knee pain question is described in Table 4. The question with the lowest sensitivity was "During the last 6 months, did knee pain last longer than a week?" (32.9\%). The question regarding pain episodes in the last month presented the highest sensitivity value (72.8\%). In general, small likelihood ratios were obtained regarding the pre and post-test probability of having radiographic $\mathrm{OA}$, showing the low ability of these questions to identify participants with knee radiographic OA.

Considering the pain score (Table 5), score -1 (participants that reported no pain) showed a high sensitivity to identify patients with knee OA (46.8\%), which probably reflects the high number of participants with knee radiographic $\mathrm{KL} \geq 2$ but without pain; however this score also presented a very low specificity (33.1\%).

Among those that reported at least one positive answer on the pain questionnaire (scores from 0 to 3 ) the ability of knee pain to identify patients with radiographic knee OA increased with increased scores. When we used only the "have you ever had knee pain" question (score 0 ) or even with score 1 ("have you ever had knee pain" and another positive question) a very low sensitivity was reached (9.3\% and $8.3 \%$, respectively) and we obtained a

Table 2 Internal consistency and factor analysis for dichotomous variables (latent trait model)

\begin{tabular}{ccc}
\hline Question & Factor loading & Cronbach's alpha if item deleted \\
\hline "In the last year did you have more than 3 knee pain episodes?" & 0.91 & 0.51 \\
"During the last 6 months did knee pain last longer than a week?" & 0.86 & 0.70 \\
"During the last month did you have knee pain?" & 0.98 & 0.46 \\
\hline Global Cronbach's Alpha & & 0.66 \\
\hline
\end{tabular}




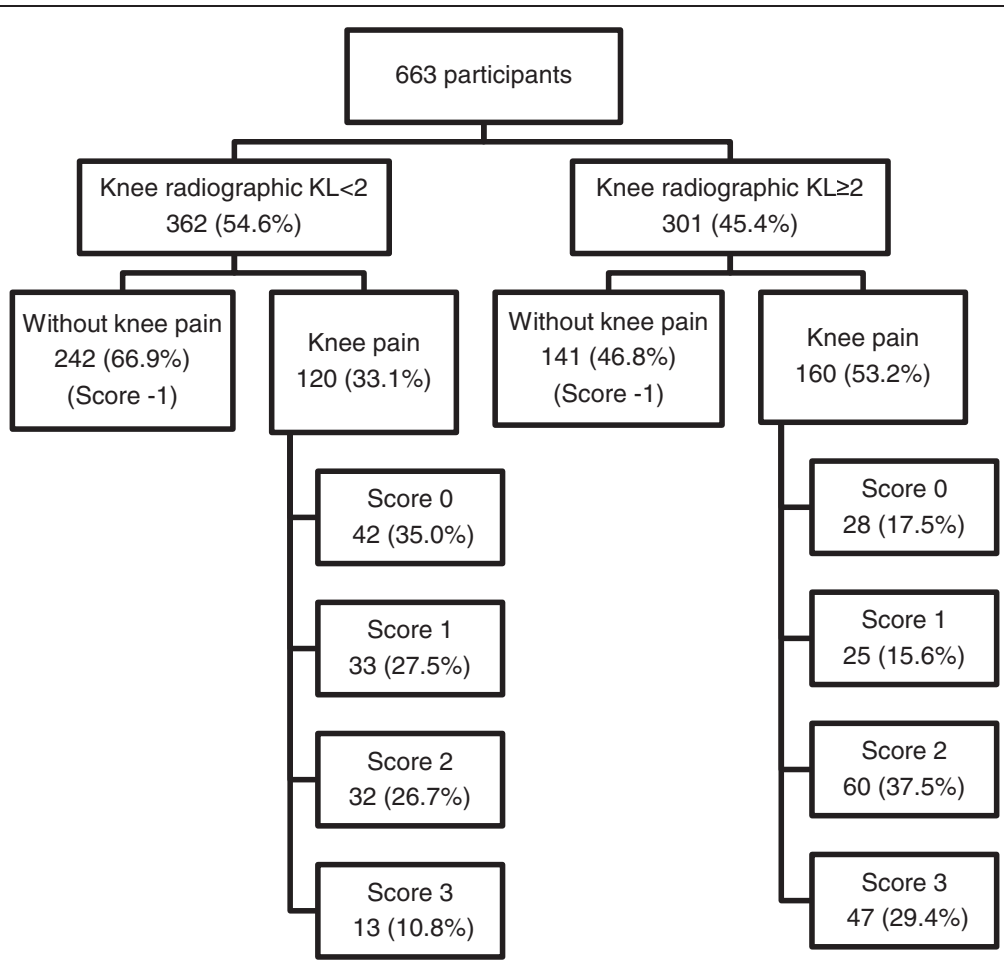

Figure 1 Distribution of participants according to knee pain and radiographic findings.

low discrimination ability (positive likelihood ratio of 0.80 and 0.91 ). Scores 2 and 3 presented a high specificity ( $>90 \%)$ but a low sensitivity $(<20 \%)$, but nevertheless this was twice as high as the sensitivity obtained with the score 1 and 2 . Based on the positive likelihood ratio, the pos-test probability of having a knee radiographic $K L \geq 2$ for those who scored 2 was twice that of the pre-test probability and this increased to 4.35 when participants scored 3. Similar results were found by sex. However, additional positive answers in males contributed to higher likelihood ratios than in females (Table 5).

To analyze the role of depressive symptoms in the discrimination ability of knee pain to identify individuals with radiographic OA, we decided not to stratify by sex in order to have enough power. The prevalence of depression (BDI > 14) was $19.9 \%$ among participants with radiographic $\mathrm{KL} \geq 2$ and $12.6 \%$ in those with radiographic $\mathrm{KL}<2(p=0.01)$. Among participants with BDI $\leq 14$ additional positive answers (increased knee pain score)

Table 3 Association between radiographic score and knee pain score, according to depressive symptoms

\begin{tabular}{|c|c|c|c|c|c|}
\hline & \multirow{3}{*}{$\begin{array}{l}\text { Knee } \\
\text { pain } \\
\text { score }\end{array}$} & \multicolumn{2}{|c|}{ Radiographic score } & \multirow{3}{*}{$\begin{array}{c}\text { Crude } \\
\text { odds ratio* }\end{array}$} & \multirow{3}{*}{$\begin{array}{c}\text { Adjusted } \\
\text { odds ratio** }\end{array}$} \\
\hline & & $\mathrm{KL}<2$ & $\mathrm{KL} \geq \mathbf{2}$ & & \\
\hline & & n (\%) & n (\%) & & \\
\hline & -1 & $222(70.3)$ & $128(53.1)$ & 1 (reference category) & 1 (reference category) \\
\hline & 0 & $38(12.0)$ & $24(10.0)$ & $1.10(0.63 ; 1.91)$ & $0.85(0.46 ; 1.58)$ \\
\hline \multirow[t]{5}{*}{$\mathrm{BDI}<14$} & 1 & $27(8.5)$ & $21(8.7)$ & $1.35(0.73 ; 2.48)$ & $1.03(0.51 ; 2.07)$ \\
\hline & 2 & $24(7.6)$ & 40 (16.6) & $2.89(1.67 ; 5.01)$ & $2.28(1.21 ; 4.30)$ \\
\hline & 3 & $5(1.6)$ & $28(11.6)$ & $9.71(3.66 ; 25.78)$ & $5.37(1.90 ; 15.18)$ \\
\hline & -1 & $20(43.5)$ & $13(21.7)$ & 1 (reference category) & 1 (reference category) \\
\hline & 0 & $4(8.7)$ & $4(6.7)$ & $1.54(0.33 ; 7.26)$ & $1.68(0.35 ; 8.18)$ \\
\hline \multirow[t]{3}{*}{$\mathrm{BDI} \geq 14$} & 1 & $6(13.0)$ & $4(6.7)$ & $1.03(0.24 ; 4.35)$ & $1.14(0.25 ; 5.14)$ \\
\hline & 2 & $8(17.4)$ & $20(33.3)$ & $3.85(1.31 ; 11.29)$ & $3.60(1.17 ; 11.07)$ \\
\hline & 3 & $8(17.4)$ & $19(31.7)$ & $3.65(1.24 ; 10.78)$ & $2.73(0.84 ; 8.86)$ \\
\hline
\end{tabular}

*Crude odds ratio for radiographic $\mathrm{OA}(\mathrm{KL} \geq 2) ;{ }^{* *}$ Adjusted odds ratio for age, body mass index (BMI) and gender. 
Table 4 Diagnostic accuracy of each knee pain question to identify participants with knee radiographic KL $\geq 2$, total and by sex

\begin{tabular}{|c|c|c|c|c|c|c|c|c|c|c|c|c|}
\hline \multirow[t]{2}{*}{ Question } & \multicolumn{4}{|c|}{ All participants } & \multicolumn{4}{|c|}{ Female } & \multicolumn{4}{|c|}{ Male } \\
\hline & $\begin{array}{c}n \\
(\%)\end{array}$ & $\begin{array}{c}\text { Sensitivity } \\
\%\end{array}$ & $\begin{array}{c}1- \\
\text { Specificity }\end{array}$ & $\begin{array}{c}\text { Like- } \\
\text { lihood } \\
\text { Ratio }\end{array}$ & $\begin{array}{c}n \\
(\%)\end{array}$ & $\begin{array}{c}\text { Sensitivity } \\
\%\end{array}$ & $\begin{array}{c}1- \\
\text { Specificity }\end{array}$ & $\begin{array}{c}\text { Like- } \\
\text { lihood } \\
\text { Ratio }\end{array}$ & $\begin{array}{c}n \\
(\%)\end{array}$ & $\begin{array}{c}\text { Sensitivity } \\
\%\end{array}$ & $\begin{array}{c}1- \\
\text { Specificity } \\
\%\end{array}$ & $\begin{array}{c}\text { Like- } \\
\text { lihood } \\
\text { Ratio }\end{array}$ \\
\hline $\begin{array}{l}\text { "Have you ever had } \\
\text { knee pain not } \\
\text { related with any } \\
\text { trauma or injury?" } \\
\text { (yes) }\end{array}$ & $\begin{array}{c}280 \\
(42.2)\end{array}$ & 53.2 & 33.2 & 1.60 & $\begin{array}{c}192 \\
(51.8)\end{array}$ & 63.9 & 41.6 & 1.54 & $\begin{array}{c}88 \\
(30.1)\end{array}$ & 39.4 & 22.5 & 1.75 \\
\hline $\begin{array}{l}\text { "In the last year did } \\
\text { you have more than } \\
3 \text { knee pain } \\
\text { episodes?"(yes) }\end{array}$ & $\begin{array}{c}172 \\
(61.0)\end{array}$ & 71.4 & 47.0 & 1.52 & $\begin{array}{c}131 \\
(68.2)\end{array}$ & 78.7 & 54.8 & 1.44 & $\begin{array}{c}41 \\
(45.6)\end{array}$ & 56.6 & 29.7 & 1.90 \\
\hline $\begin{array}{l}\text { "During the last } \\
6 \text { months did knee } \\
\text { pain last longer than } \\
\text { a week?"(yes) }\end{array}$ & $\begin{array}{c}72 \\
(25.5)\end{array}$ & 32.9 & 15.7 & 2.10 & $\begin{array}{c}50 \\
(26.0)\end{array}$ & 33.3 & 16.7 & 2.0 & $\begin{array}{c}22 \\
(24.4)\end{array}$ & 32.1 & 13.5 & 2.37 \\
\hline $\begin{array}{l}\text { "During the last } \\
\text { month did you have } \\
\text { knee pain?" (yes) }\end{array}$ & $\begin{array}{c}178 \\
(62.9)\end{array}$ & 72.8 & 49.6 & 1.47 & $\begin{array}{c}131 \\
(67.9)\end{array}$ & 76.1 & 57.1 & 1.33 & $\begin{array}{c}47 \\
(52.2)\end{array}$ & 66.0 & 32.4 & 2.04 \\
\hline
\end{tabular}

allowed an increase in the positive likelihood ratio: those with score 2 had twice the probability of having radiographic $K L \geq 2$ than before the questions and this increased to 7.34 for those who scored 3. In the presence of depressive symptoms BDI $>14$ the ability of these questions to identify participants with radiographic knee OA became lower, with a positive likelihood ratio of 1.92 for those who scored 2 and 1.82 for those who scored 3 (Table 6).

\section{Discussion}

In our study, a high proportion of participants had radiographic findings but did not report knee pain $(21.3 \%)$. This is in accordance with previous data $[1,32-34]$. Pain is the most frequent complaint in OA and frequently the first reason for consulting a physician [12]. It is an unspecific symptom and its expression may be associated with other conditions than OA [34,35], making pain assessment a relevant but difficult issue [36]. We found that participants with higher pain scores had higher odds of having depressive symptoms. Additionally, a higher association of knee pain with radiographic knee OA was found in participants without depressive symptoms. The probability of a participant having radiographic $\mathrm{KL} \geq 2$ rose substantially with the number of positive answers to knee pain questions (increased pain scores). This is more obvious in score 2 and 3 where the higher likelihood ratios were found. These results reinforce our idea that using a score was better than using each separate question and they were

Table 5 Diagnostic accuracy of knee pain scores to identify participants with knee radiographic $\mathrm{KL} \geq \mathbf{2}$, total and by sex

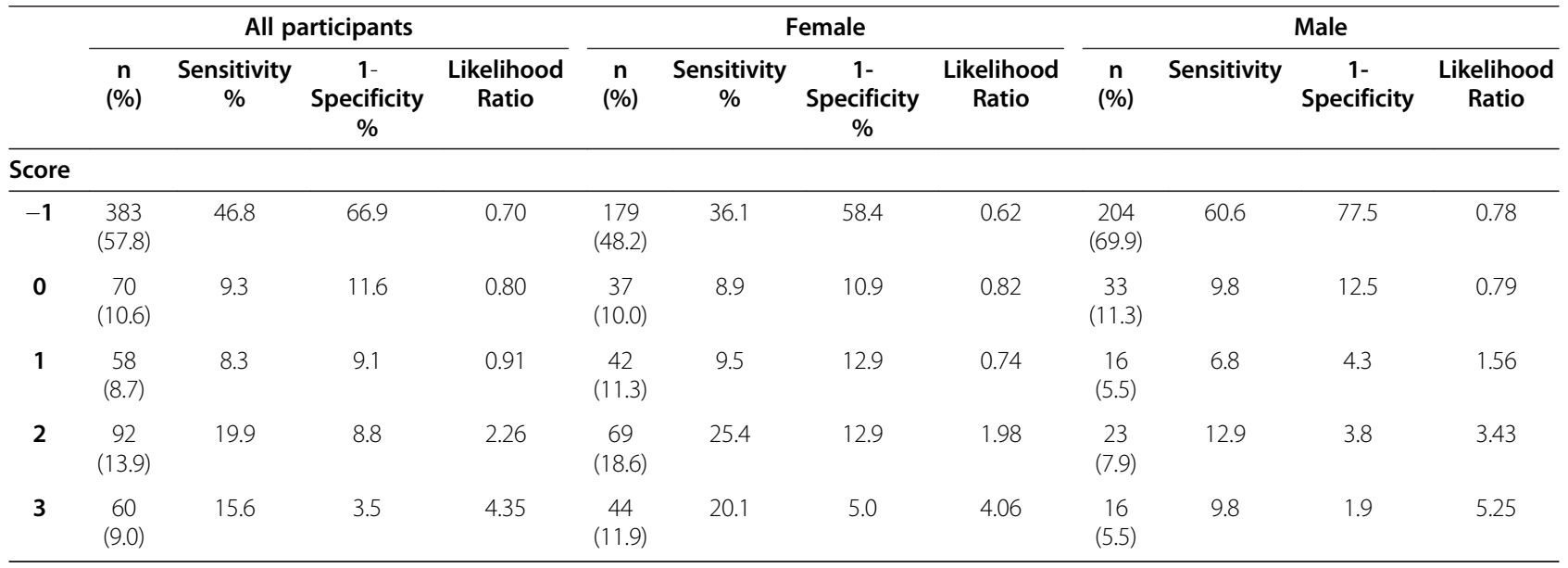


Table 6 Diagnostic accuracy of knee pain scores to identify patients with and without radiographic knee OA, according to depressive symptoms

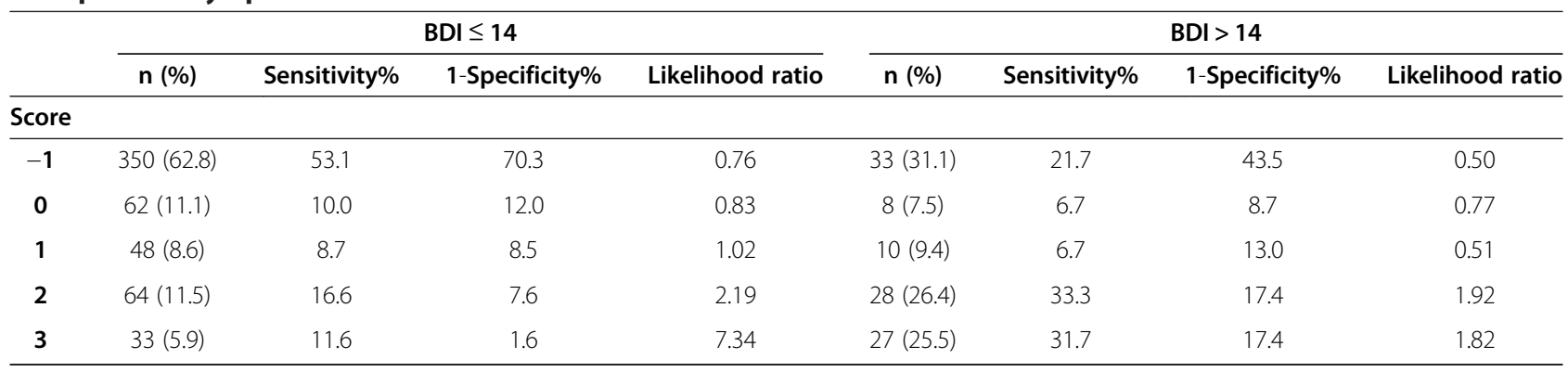

in accordance with previous studies showing a lower ability of individual questions on knee pain for the diagnosis of OA [11].

Our results were consistent in females and males, but positive answers in males contributed to higher likelihood ratios than in females. This may be explained by sex differences in pain perception, evaluation, and reporting, with females reporting pain more frequently than males, which may make these symptoms more unspecific in females [37-39].

Since, in general, our data showed similar results by sex, and in order to improve the statistical power, we decided to analyze the role of depressive symptoms not stratifying by sex. Among participants with BDI $\leq 14$ the likelihood ratio to identify patients with radiographic knee OA increased with increased pain scores reaching 7.34 when participants responded positively to all pain questions (score 3 ). In the presence of depressive symptoms (BDI > 14) our score became unable to identify participants with radiographic knee OA since the likelihood ratios ranged from 0.77 for those with one positive answer (score 0) to 1.82 for those with all positive answers (score 3). These results are in accordance with other studies that show that depressive symptoms can change pain perception and contribute to pain over-expression $[20,35,40]$. Thus, in the presence of depressive symptoms, pain becomes more unspecific so the ability of pain complains to allow the identification of patients with radiographic $\mathrm{OA}$ is lower.

It is important to highlight that our data was from a population-based study and participants had low depressive symptomatology [median of 7 (25th-75th percentile: $3-12)$ ]. It can be argued that in populations with more prevalent depressive symptoms, such as older populations or those with higher co-morbidities, knee pain can even have a lower discrimination ability to identify participants with $\mathrm{OA}$.

On the other hand, among participants with depressive symptoms, pain questions could be useful to identify those without disease, since negative answers (reporting no pain) allowed the best specificity (57\%) and a positive likelihood ratio of 0.50 .
Considering all participants, the score -1 , corresponding to participants that reported no pain, was unable to efficiently discriminate participants according to radiographic OA findings (it presented a high sensitivity, but a very low specificity and the lowest likelihood ratio). So, reporting "no knee pain" was not enough to accurately identify participants without radiographic OA. However, stratified analysis by depressive symptoms, showed that among participants with depressive symptoms the specificity of score -1 rose to almost $60 \%$, showing that in this group of participants reporting "no knee pain" may be a better marker to identify participants without radiographic OA.

Pain related to $\mathrm{OA}$ is associated with an increased risk of worse psychological outcomes, including anxiety, depression and helplessness $[15,18,41]$. Since our data is based on a cross-sectional study, it is impossible to understand if depressive symptoms are responsible for OA pain manifestations or whether they are caused by OA pain. However, this was not the purpose of our study. We tried to understand if the presence of depressive symptoms, regardless of their causes, may influence knee pain expression and its ability to identify patients with relevant radiographic OA findings.

We tried to minimize the problem of pain assessment using questions with different time frames. Nevertheless, the ability of knee pain to identify participants with radiographic OA would probably improve with a higher number of questions; however, we tried to use a small number of easy questions, which could be easily used in a clinical setting or in population based studies.

One limitation of our study was the inability to explore other common features of OA such as stiffness, loss of joint mobility, swelling, tenderness, joint deformity and muscle weakness. However, pain is thought to be one of the aspects that is more correlated with radiographic symptomatic changes [10] and is also highly associated to the other OA signs and symptoms, namely disability $[32,42]$. So we could expect a similar effect of depressive symptoms on those signs and symptoms.

In our study radiographic OA was defined as Kellgren Lawrence score of 2-4, and some reliability and validity 
limitations of this grading scale can be discuss [43]. Our radiographs were scored only by one experienced reader that was unaware of the participants' clinical data. We used a cut off point $\geq 2$ to define radiographic OA which is also a controversial aspect $[26,27]$. Since differences would be expected in the relation between pain and radiographic changes according to disease severity [21], we performed the same analyses using $K L \geq 3$ as cut off point and we found a slight improvement in the ability of knee pain to identify participants with radiographic OA, but those differences disappeared among those with depressive symptoms (data not shown).

Although our study was developed from a populationbased study, we lost almost 33\% of the participants for our research, which could determine a selection bias. Nevertheless, non-participants were quite similar to the studied population although younger. Thus, despite some limitations, our results support the idea that psychological status deserves greater clinical and research attention in OA, since the presence of depressive symptoms impairs the ability of pain complaints to identify potential OA patients or to correctly manage the disease in those already diagnosed. The evaluation and treatment of depressive symptoms should be an integrative part of OA patient management, in order to improve it and to ensure that knee pain expression can be correctly understood.

\section{Conclusions}

Our study highlights the importance of a more comprehensive understanding of pain complaints to improve our ability to identify individuals with OA and to apply rational treatment strategies.

Knee pain was associated both with depressive symptoms and radiographic OA. Single questions on knee pain symptoms do not allow the identification of patients with radiographic OA, but better discrimination ability was found using a score of four questions, with higher scores showing the higher discrimination ability in both sexes. However, the presence of depressive symptoms impairs the ability of knee pain complaints in OA diagnosis and management.

\section{Competing interests}

The authors declare that they have no competing interests.

\section{Authors' contributions}

DP and ER participated in the study conception, design and drafting. RAS was involved in the data collection and study design. MS performed the statistical analysis and participated in data interpretation. JB and HB were involved in revising it critically for important intellectual content. All authors read and approved the final manuscript.

\section{Acknowledgements}

No sources of funding or further contributions need to be reported.

\section{Author details}

'Department of Clinical Epidemiology, Predictive Medicine and Public Health, University of Porto Medical School, Alameda Prof. Hernâni Monteiro, 4200-319 Porto, Portugal. ${ }^{2}$ Public Health Institute, University of Porto, Porto, Portugal. ${ }^{3}$ CEDOC, Nova Medical School / Faculdade de Ciências Médicas, Universidade Nova de Lisboa; Rheumatology Department, CHLO,EPE Hospital Egas Moniz, Lisboa, Portugal. ${ }^{4}$ Beatriz Ângelo Hospital, Loures, Portugal.

Received: 22 January 2013 Accepted: 12 July 2013

Published: 22 July 2013

\section{References}

1. Odding E, Valkenburg HA, Algra D, Vandenouweland FA, Grobbee DE, Hofman A: Associations of radiological osteoarthritis of the hip and knee with locomotor disability in the Rotterdam Study. Ann Rheum Dis 1998, 57(4):203-208.

2. Zhang Y, Xu L, Nevitt MC, Aliabadi P, Yu W, Qin M, Lui LY, Felson DT: Comparison of the prevalence of knee osteoarthritis between the elderly Chinese population in Beijing and whites in the United States: the Beijing osteoarthritis study. Arthritis Rheum 2001, 44(9):2065-2071.

3. March LM, Schwarz JM, Carfrae BH, Bagge E: Clinical validation of self-reported osteoarthritis. Osteoarthr Cartil 1998, 6(2):87-93.

4. Sun BH, Wu CW, Kalunian KC: New developments in osteoarthritis. Rheum Dis Clin North Am 2007, 33(1):135-148.

5. Woolf A, Pfleger B: Burden of major musculoskeletal conditions. 2003, 81(9):646-656.

6. Arden N, Nevitt MC: Osteoarthritis: epidemiology. Best Pract Res Clin Rheumatol 2006, 20(1):3-25.

7. Cooper C, Snow S, McAlindon TE, Kellingray S, Stuart B, Coggon D, Dieppe PA: Risk factors for the incidence and progression of radiographic knee osteoarthritis. Arthritis Rheum 2000, 43(5):995-1000.

8. Lau EC, Cooper C, Lam D, Chan VN, Tsang KK, Sham A: Factors associated with osteoarthritis of the hip and knee in Hong Kong Chinese: obesity, joint injury, and occupational activities. Am J Epidemio/ 2000, 152(9):855-862.

9. Peat G, Thomas E, Duncan R, Wood L, Hay E, Croft P: Clinical classification criteria for knee osteoarthritis: performance in the general population and primary care. Ann Rheum Dis 2006, 65(10):1363-1367.

10. Sanghi D, Avasthi S, Mishra A, Singh A, Agarwal S, Srivastava RN: Is radiology a determinant of pain, stiffness, and functional disability in knee osteoarthritis? A cross-sectional study. J Orthop Sci 2011, 16(6):719-725.

11. Zhang W, Doherty M, Peat G, Bierma-Zeinstra MA, Arden NK, Bresnihan B, Herrero-Beaumont G, Kirschner S, Leeb BF, Lohmander LS, et al: EULAR evidence-based recommendations for the diagnosis of knee osteoarthritis. Ann Rheum Dis 2010, 69(3):483-489.

12. Kopec JA, Rahman MM, Berthelot JM, Le Petit C, Aghajanian J, Sayre EC, Cibere J, Anis AH, Badley EM: Descriptive epidemiology of osteoarthritis in British Columbia. Canada. J Rheumatol 2007, 34(2):386-393.

13. Davis MA, Ettinger WH, Neuhaus JM, Barclay JD, Segal MR: Correlates of knee pain among US adults with and without radiographic knee osteoarthritis. J Rheumatol 1992, 19(12):1943-1949.

14. Lawrence RC, Helmick CG, Arnett FC, Deyo RA, Felson DT, Giannini EH, Heyse SP, Hirsch R, Hochberg MC, Hunder GG, et al: Estimates of the prevalence of arthritis and selected musculoskeletal disorders in the United States. Arthritis Rheum 1998, 41(5):778-799.

15. Hawker GA, Gignac MA, Badley E, Davis AM, French MR, Li Y, Perruccio AV, Power JD, Sale J, Lou W: A longitudinal study to explain the pain-depression link in older adults with osteoarthritis. Arthritis Care Res (Hoboken) 2011, 63(10):1382-1390.

16. Neogi T, Felson D, Niu J, Nevitt M, Lewis CE, Aliabadi P, Sack B, Torner J, Bradley $L$, Zhang $Y$ : Association between radiographic features of knee osteoarthritis and pain: results from two cohort studies. BMJ 2009, 339:b2844.

17. Liew HP: Depression and chronic illness: a test of competing hypotheses. J Health Psychol 2012, 17(1):100-109.

18. Axford J, Heron C, Ross F, Victor CR: Management of knee osteoarthritis in primary care: pain and depression are the major obstacles. $J$ Psychosom Res 2008, 64(5):461-467.

19. He $Y$, Zhang $M$, Lin EH, Bruffaerts R, Posada-Villa J, Angermeyer MC, Levinson D, de Girolamo G, Uda H, Mneimneh Z, et al: Mental disorders among persons with arthritis: results from the World Mental Health Surveys. Psychol Med 2008, 38(11):1639-1650. 
20. Neogi T, Nevitt MC, Yang M, Curtis JR, Torner J, Felson DT: Consistency of knee pain: correlates and association with function. Osteoarthr Cartil 2010, 18(10):1250-1255.

21. Duncan R, Peat G, Thomas E, Hay E, McCall I, Croft P: Symptoms and radiographic osteoarthritis: not as discordant as they are made out to be? Ann Rheum Dis 2007, 66(1):86-91.

22. Ramos $E_{\text {, Lopes }}$, Barros $H$ : Investigating the effect of nonparticipation using a population-based case-control study on myocardial infarction. Ann Epidemiol 2004, 14(6):437-441.

23. Beck AT, Ward CH, Mendelson M, Mock J, Erbaugh J: An inventory for measuring depression. Arch Gen Psychiatry 1961, 4:561-571.

24. Vaz-Serra A, Abreu J: Aferição dos quadros clínicos depressivos: I. ensaio de aplicação do Inventário Depressivo de Beck a uma amostra portuguesa de doentes deprimidos. Coimbra Med 1973, 20:623-644.

25. Oliveira A, Ramos E, Lopes C, Barros H: Self-reporting weight and height: misclassification effect on the risk estimates for acute myocardial infarction. Eur J Public Health 2009, 19(5):548-553.

26. Altman R, Asch E, Bloch D, Bole G, Borenstein D, Brandt K, Christy W, Cooke $T D$, Greenwald R, Hochberg M, et al: Development of criteria for the classification and reporting of osteoarthritis. Classification of osteoarthritis of the knee. Diagnostic and Therapeutic Criteria Committee of the American Rheumatism Association. Arthritis Rheum 1986, 29(8):1039-1049.

27. Dahaghin S, Bierma-Zeinstra SM, Ginai AZ, Pols HA, Hazes JM, Koes BW: Prevalence and pattern of radiographic hand osteoarthritis and association with pain and disability (the Rotterdam study). Ann Rheum Dis 2005, 64(5):682-687.

28. Cortina JM: What is coefficient alpha? An examination of theory and applications. J Appl Psychol 1993, 78:98-104.

29. Terwee CB, Bot SD, de Boer MR, van der Windt DA, Knol DL, Dekker J, Bouter $L M$, de Vet HC: Quality criteria were proposed for measurement properties of health status questionnaires. J Clin Epidemio/ 2007, 60(1):34-42

30. Altman DG, Bland JM: Diagnostic tests. 1: sensitivity and specificity. BMJ 1994, 308(6943):1552.

31. Deeks JJ, Altman DG: Diagnostic tests 4: likelihood ratios. BMJ 2004, 329(7458):168-169.

32. Barker K, Lamb SE, Toye F, Jackson S, Barrington S: Association between radiographic joint space narrowing, function, pain and muscle power in severe osteoarthritis of the knee. Clin Rehabil 2004, 18(7):793-800.

33. Jordan KM, Arden NK, Doherty M, Bannwarth B, Bijlsma JW, Dieppe P, Gunther K, Hauselmann H, Herrero-Beaumont G, Kaklamanis P, et al: EULAR Recommendations 2003: an evidence based approach to the management of knee osteoarthritis: report of a Task Force of the Standing Committee for International Clinical Studies Including Therapeutic Trials (ESCISIT). Ann Rheum Dis 2003, 62(12):1145-1155.

34. Bedson J, Croft PR: The discordance between clinical and radiographic knee osteoarthritis: a systematic search and summary of the literature. BMC Musculoskelet Disord 2008, 9:116.

35. Somers TJ, Keefe FJ, Godiwala N, Hoyler GH: Psychosocial factors and the pain experience of osteoarthritis patients: new findings and new directions. Curr Opin Rheumatol 2009, 21(5):501-506.

36. O'Reilly SC, Muir KR, Doherty M: Screening for pain in knee osteoarthritis: which question? Ann Rheum Dis 1996, 55(12):931-933.

37. Nicassio PM: Understanding the role and significance of gender differences in pain and depression in Chinese elders with osteoarthritis. Pain 2007, 130(1-2):6-7.

38. Schechtman KB, Kutner NG, Wallace RB, Buchner DM, Ory MG: Gender, self-reported depressive symptoms, and sleep disturbance among older community-dwelling persons. FICSIT group. Frailty and injuries: Cooperative Studies of Intervention Techniques. J Psychosom Res 1997, 43(5):513-527.

39. Tonelli SM, Rakel BA, Cooper NA, Angstom WL, Sluka KA: Women with knee osteoarthritis have more pain and poorer function than men, but similar physical activity prior to total knee replacement. Biol Sex Differ 2011, 2:12.

40. Wise BL, Niu J, Zhang Y, Wang N, Jordan JM, Choy E, Hunter DJ: Psychological factors and their relation to osteoarthritis pain. Osteoarthr Cartil 2010, 18(7):883-887.

41. Parmelee PA, Harralson TL, McPherron JA, DeCoster J, Schumacher HR: Pain, disability, and depression in osteoarthritis: effects of race and sex. J Aging Health 2012, 24(1):168-187.
42. Creamer $P$, Lethbridge-Cejku M, Hochberg MC: Factors associated with functional impairment in symptomatic knee osteoarthritis. Rheumatology (Oxford) 2000, 39(5):490-496.

43. Duncan RC, Hay EM, Saklatvala J, Croft PR: Prevalence of radiographic osteoarthritis-it all depends on your point of view. Rheumatology (Oxford) 2006, 45(6):757-760

doi:10.1186/1471-2474-14-214

Cite this article as: Pereira et al:: The effect of depressive symptoms on the association between radiographic osteoarthritis and knee pain: a cross-sectional study. BMC Musculoskeletal Disorders 2013 14:214.

\section{Submit your next manuscript to BioMed Central and take full advantage of:}

- Convenient online submission

- Thorough peer review

- No space constraints or color figure charges

- Immediate publication on acceptance

- Inclusion in PubMed, CAS, Scopus and Google Scholar

- Research which is freely available for redistribution

Submit your manuscript at www.biomedcentral.com/submit
C Biomed Central 